PAPERS IN PHYSICAL OCEANOGRAPHY AND METEOROLOGY Published by MASSACHUSETTS INSTITUTE OF TECHNOLOGY AND WOODS HOLE OCEANOGRAPHIC INSTITUTION VOL. V, NO. 3

\title{
THE MINIMUM OXYGEN CONGENTRATION IN THE WESTERN BASIN OF THE NORTH ATLANTIC
}

BY

H. R. SEIWELL

Contribution No. I 38 from the Woods Hole Oceanographic Institution

CAMBRIDGE AND WOODS HOLE, MASSACHUSETTS

$$
\text { May, } 1937
$$




\section{CONTENTS}

INTRODUCTION . . . . . . . . . . . . . . . . . . . . 3

Depth and Value of Minimum Oxygen Concentration . . . . . . . . 5

Regional Distribution of Minimum Oxygen Values . . . . . . . . 5

Relation of Minimum Oxygen Concentration to Physical Properties . . 7

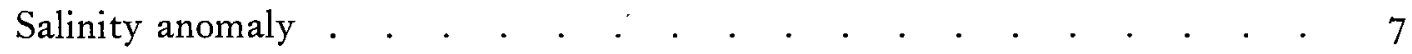

Density . . . . . . . . . . . . . . . . . . . . . 10

Physical Significance of the Origin of the Minimum Oxygen ConcentraTION . . . . . . . . . . . . . . . . . . . . . . . 15

Suggestions Concerning the Origin of the Minimum Oxygen Concentration i 8 


\section{INTRODUCTION}

With the advance in knowledge of oceanic circulation there now exists a demand for additional identifying properties which will serve to trace the origin and movements of water masses in the sea, and to check earlier conclusions based entirely on temperature and salinity distribution. Of all the known identifying properties (except temperature and salinity) oxygen appears to be the most useful, not only because of the ease with which it can be accurately measured at sea, but also because of the large amount of data available on its distribution in the open ocean.

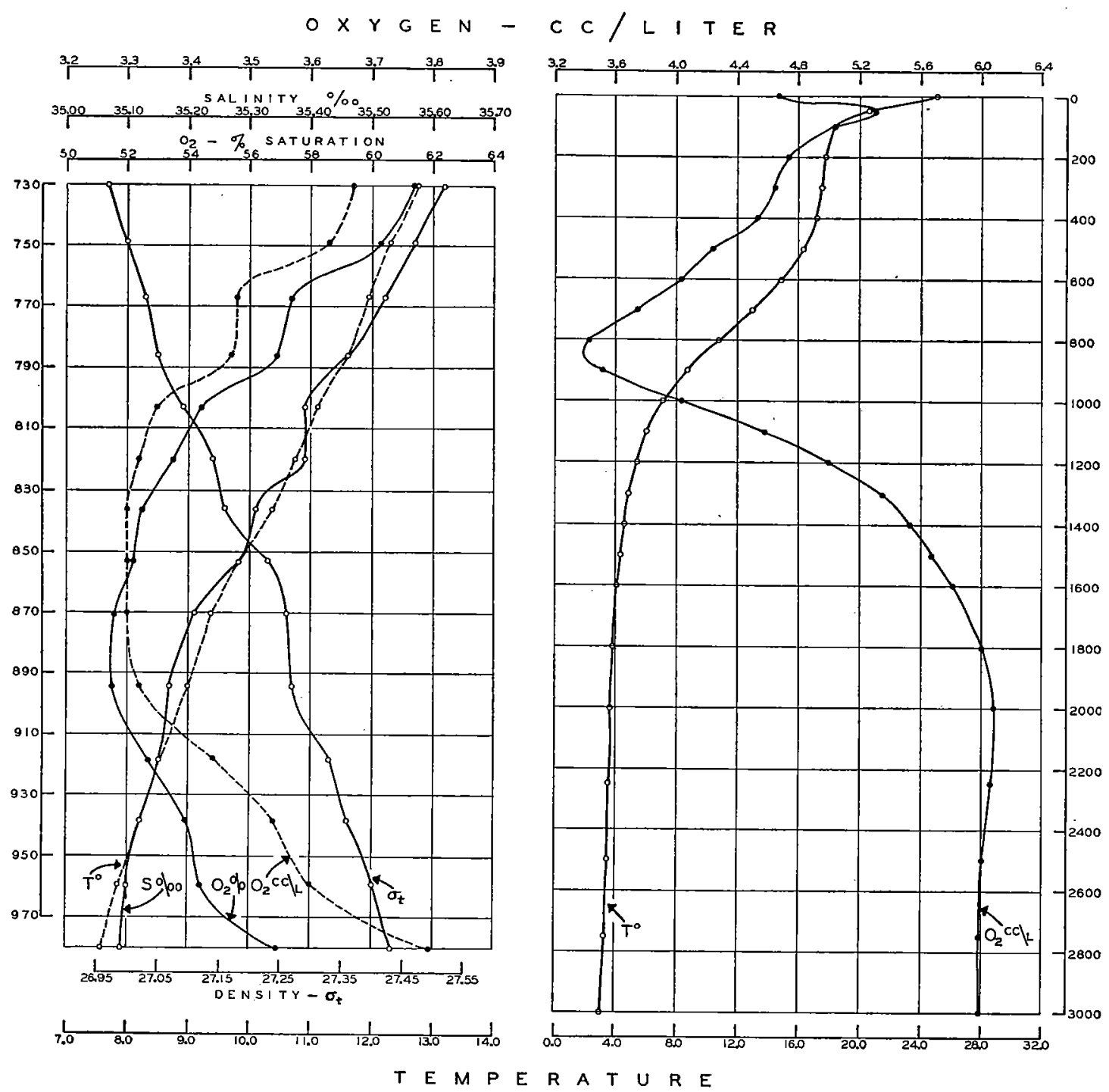

FIG. I.-At the left, detailed vertical distribution of oxygen and associated characteristics through the zone of minimum oxygen concentration ( $730^{\circ}-980$ meters) at "Atlantis" station $2639\left(66^{\circ} 25^{\prime} \mathrm{W}, 35^{\circ} \circ 7^{\prime} \mathrm{N}\right)$; at the right, mean distribution of oxygen and temperature at this station to 3000 meters depth. 
Figure I shows a characteristic curve of oxygen distribution in the Atlantic for "Atlantis" station 2639. Distinct regional departures from this particular distribution are confined to: (I) thickness of the upper, oxygen rich layer; (2) the value of the minimum concentration; and (3) the depth of the minimum concentration. In general, these three properties characterize regional variations of vertical oxygen distribution since they determine the magnitude of the vertical gradient.

Within recent years attention has been drawn to the minimum oxygen concentration at mid depths and several attempts have been made to explain the mechanism responsible for its origin and maintenance, and sufficient evidence has been accumulated to show that such knowledge is a prime requirement for physical oceanographical investigations. It is the purpose of this paper to analyze the occurrence of the minimum oxygen concentration in the western North Atlantic as shown by existing observations. 


\section{DEPTH AND VALUE OF MINIMUM OXYGEN CONCENTRATION}

The minimum concentration of oxygen in the western North Atlantic has been observed to occur generally between depths of 200 to 900 meters with values ranging from I.7 to more than $5.0 \mathrm{cc}$ per liter. In mid ocean (along the 4 oth meridian) between la titudes $50^{\circ} \mathrm{N}$ and $40^{\circ} \mathrm{N}$ minimum values in vertical distribution were observed to range from 3.54 to $5.25 \mathrm{cc}$ per liter at depths of 260 to 680 meters: between $40^{\circ} \mathrm{N}$ and $30^{\circ} \mathrm{N}$ the minimum concentration is $3.70-4.30 \mathrm{cc}$ per liter at 600 to 890 meters; between $30^{\circ} \mathrm{N}$ and $20^{\circ} \mathrm{N}$ it is $2.99^{-} 3.87 \mathrm{cc}$ per liter at depths of 780 to $94^{\circ}$ meters; between $20^{\circ} \mathrm{N}$ and $10^{\circ} \mathrm{N}$, I. $73^{-2.62} \mathrm{cc}$ per liter at 390 to 640 meters; and between $10^{\circ} \mathrm{N}$ and $0^{\circ}, 2.25-3.45 \mathrm{cc}$ per liter at depths of 340 to 600 meters. Thus, a definite north south regional variation is indicated for mid Atlantic. In an east west direction, between latitude $32^{\circ} 37^{\prime} \mathrm{N}$ and $36^{\circ} 27^{\prime} \mathrm{N}$, minimum values of 3.27 to $4.4 \circ \mathrm{cc}$ per liter at depths of 800 to 900 meters have been observed from longitude $44^{\circ} 40^{\prime} \mathrm{W}$ to $72^{\circ} 47^{\prime} \mathrm{W}$ and then, still further west, the depth of the minimum concentration rises sharply along with the isolines of temperature, salinity, and density to approximately 200 meters depth between longitude $73^{\circ} \circ 5^{\prime} \mathrm{W}$ and $74^{\circ}$ i $5^{\prime} \mathrm{W}$ (Seiwell, 1934).

\section{REGIONAL DISTRIBUTION OF MINIMUM OXYGEN VALUES}

The regional distribution of observed minimum oxygen values in the western North Atlantic is illustrated by figure 2 . Within the region to the west of longitude $40^{\circ}$ there are two centers of low minimum values and two of higher minimum values. The former are: (I) within the Gulf Stream on leaving the Straits of Florida (values of less than 3.0 cc per liter were observed up to $\left.35^{\circ} \mathrm{N}\right)$; and (2) in the southeastern part of the area investigated (values less than $2.0 \mathrm{cc}$ per liter were observed by "Atlantis" at latitude I 2 " in mid ocean). The two centers of high minimum values in this side of the Atlantic are: (I) at the western boundary of the region, in mid Atlantic, at about $35^{\circ} \mathrm{N}$ latitude (values more than $4.00 \mathrm{cc}$ per liter) and (2) at the northeast sector of the region north of latitude $45^{\circ} \mathrm{N}$ (values more than $4.0 \mathrm{cc}$ per liter were observed by "Atlantis" at latitude $47^{\circ} \mathrm{N}$ ). Mixing of the various water masses produces the general pattern outlined in figure 2:

However, in arriving at the minimum oxygen values, and the associated relationships, consideration should be given to the manner in which they have been determined so that not too much significance be attached to the observed readings.

Examination of figure I may clarify this point. The minimum oxygen value occurs in the most stable part of the water column where the vertical gradients of all observed characteristics are most strongly developed and, consequently, unless the vertical sampling interval through this layer is very small (e.g., about 20 meters), artificial variations of the minimum oxygen value and its associated temperature, density, etc., may be produced solely as a result of the sampling. And, it is obvious that any sort of oceanographic samplings will not in general give exact minimum oxygen values, unless, as has rarely been the case, special effort is made to measure the true minimum oxygen value by significant departures from the regular station routine (page 15 ).

The probability that the actual minimum oxygen value is measured in a series of samplings over an oceanic area will primarily depend on: (a) the thickness of a finite 


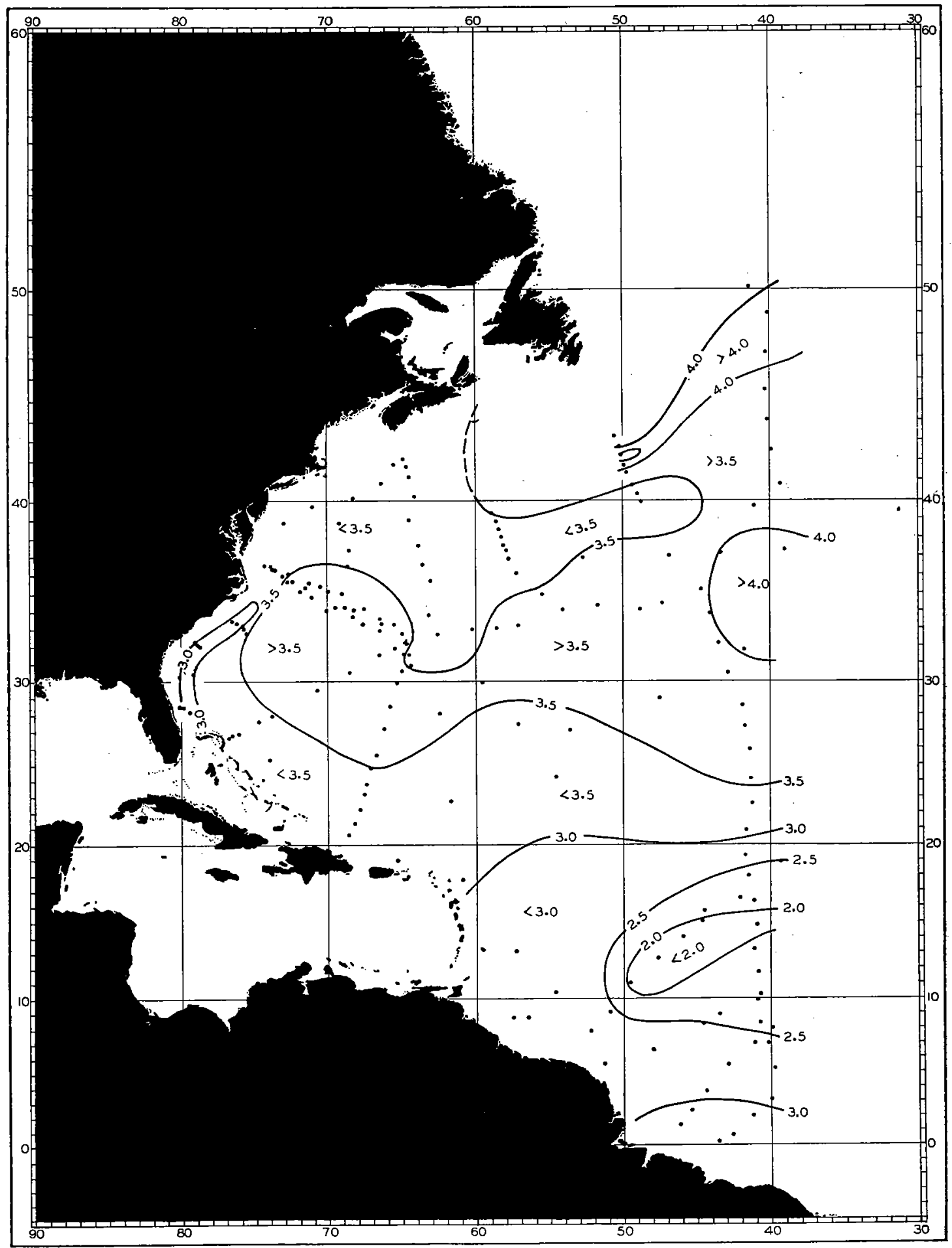

Fig. 2.-Regional distribution of observed_minimum oxygen values in the western North Atlantic. 
layer of water throughout which, because of the limit of accuracy of the oxygen methods, significant increases above the minimum value cannot be detected; and (b) the vertical width of the sampling interval. From the data of station 2639 (page I 5 ) it appears that, for the region represented, the thickness of the water layer throughout which no significant increases above the lowest observed value can be detected is approximately 35 meters. Hence, with the water bottles spaced approximately 200 meters apart on the attached wire the probability of sampling the lowest oxygen concentration (within limits of error of the measurement) for a case of random sampling would be approximately I/6. Since in the western North Atlantic oceanographic sampling may be considered in general as random a special treatment is required to ascertain the most probable relationships at the depth of the minimum oxygen concentration.

An investigation of density, $\sigma_{t}$, at the depth of the minimum oxygen concentration in the western North Atlantic shows, as explained on page I $_{4}$, that the modal value of $\sigma_{t}$ is $27.232 \neq 0.008$. Thus, an adjusted minimum oxygen value (along the constant density surface $\sigma_{t}=27.232$ ) can be obtained by plotting the observed oxygen values for individual stations as a function of $\sigma_{t}$ and fitting a smooth curve to the points so its point of inflection occurs at $\sigma_{t}=27.232$. To test the amount of variation which might be expected between the observed and adjusted minimum oxygen values the quantity $\mathrm{O}_{20 \text { served }}-\mathrm{O}_{2 \text { adjusted }}$ was obtained for 75 stations in the western North Atlantic; the percental frequency distribution of these differences is given in table I. The maximum amount of reduction in value of the observed minimum concentration was $0.16 \mathrm{cc}$ per liter.

Range cc/liter

Per cent distribution

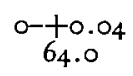

TABLE 1

Thus, in general, for all practical purposes the distribution of minimum oxygen values in the western North Atlantic is shown by figure 2. However, when detailed knowledge of the minimum oxygen concentration is required it is recommended that the adjusted minimum values be used in preference to those observed.

\section{RELATION OF MINIMUM OXYGEN CONCENTRATION TO PHYSICAL PROPERTIES}

\section{Salinity Anomaly}

Classification of the various water types at the depth of the oxyxen minimum may be made on the basis of deviations from the mean salinity anomaly, $D$, the values of which are plotted in figure 3 .

In determining the latter use has been made of Helland-Hansen's normal temperature salinity relationship for northern North Atlantic water. ${ }^{1}$ Thus:

$$
S_{\iota}^{\circ} \%=34.737+0.038 t+0.0029 t^{2}
$$

from which a salinity anomaly is calculated:

$$
\text { S.A. }=\mathrm{I} 00\left(S^{\circ} / \mathrm{oo}-S_{t} \% \text { oo }\right)
$$

where $S$ is the observed salinity and $S_{t}$ the calculated "normal" salinity. The mean

\footnotetext{
${ }^{1}$ Helland-Hansen (1930).
} 


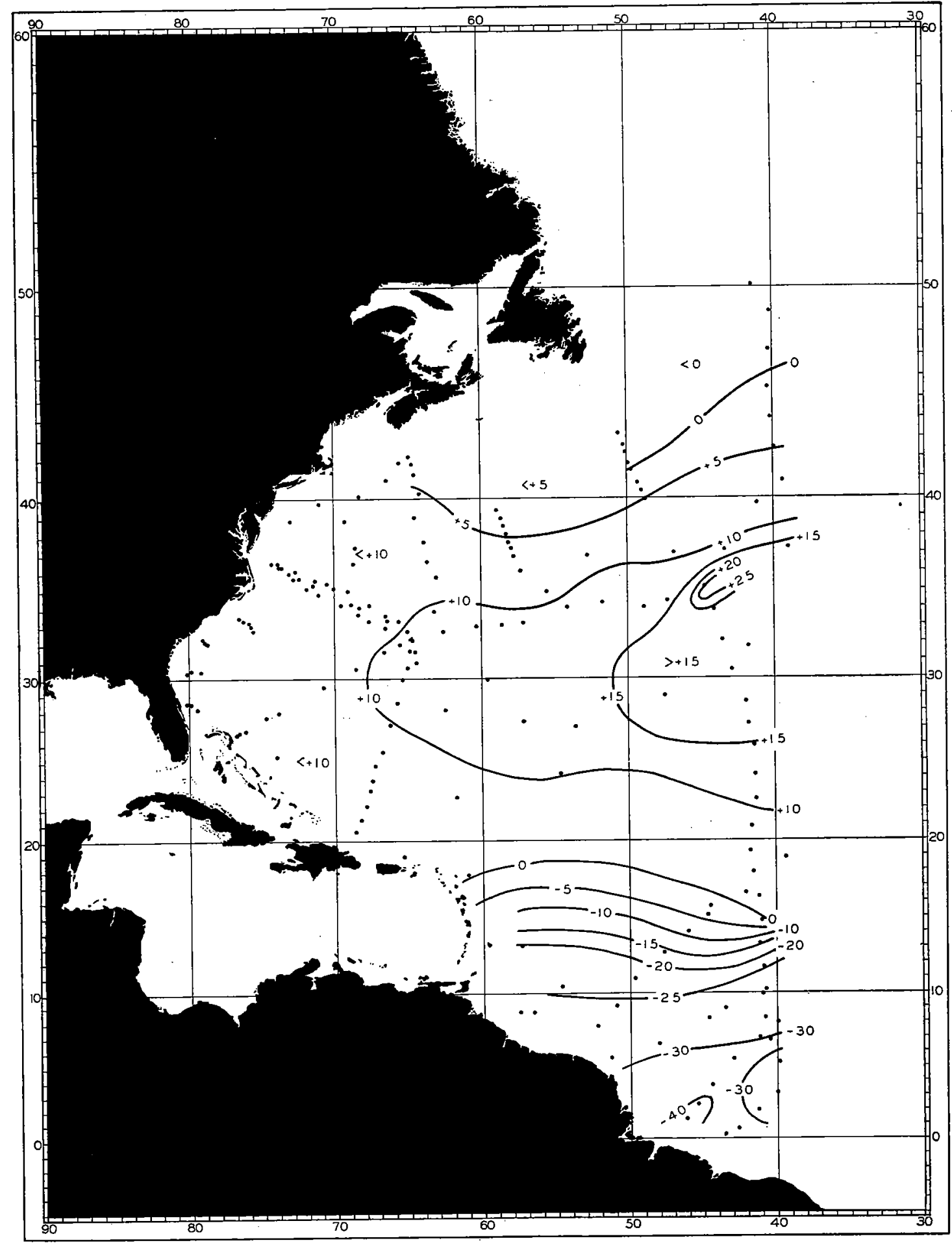

FIG. 3.-Regional distribution of $D$ values, representing deviations from the mean salinity anomaly, at the observed depth of minimum oxygen concentration in the western North Atlantic (see text). 
salinity anomaly at the depth of the observed oxygen minimum in the region under consideration was calculated (on the basis of existing observations) and the deviations from the mean determined. Thus:

$$
D=\text { S.A. }-\overline{\text { S.A. }}
$$

where S.A. is the calculated salinity anomaly and S.A. the mean of all anomalies for the region. The quantity $D$ is based on the original form of the temperature salinity correlation as deduced by Helland-Hansen; positive values indicate that the water contains more salt than normal for the western Atlantic with respect to a given temperature, whereas negative values of $D$ characterize water with less salt than normal. Thus, accord-

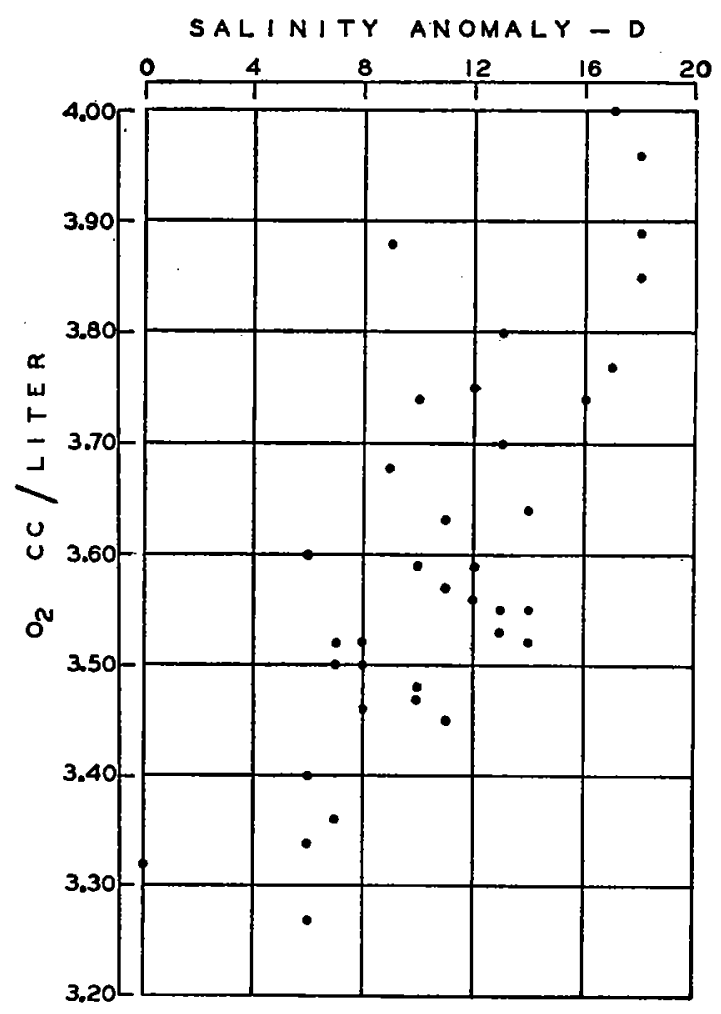

Fig. 4.-Correlation of $D$ values and observed minimum oxygen values across the western North Atlantic basin between latitude $25^{\circ} \mathrm{N}$ and $35^{\circ} \mathrm{N}$. Correlation coefficient $r=0.782$.

ing to modern concepts, at the depth of the minimum oxygen value high positive values of $D$ are presumably due to the influence of the Mediterranean in the western North Atlantic whereas low negative values of $D$ in the southern half of the region are caused by mixture with subantarctic water which spreads out into the North Atlantic at the levels in question.

A comparison of figures 2 and 3 shows a good general correlation between the observed minimum oxygen values and the values of $D$. The high negative values of $D$ in the southeastern part of the area (the result of subantarctic water) are associated with low minimum oxygen values. The tongue of relatively high minimum values extending 
through the center of the region, approximately between latitudes $25^{\circ} \mathrm{N}$ and $35^{\circ} \mathrm{N}$, is associated with high positive values of $D$, suggesting that one effect of the influence of the Mediterranean in the western North Atlantic is to raise the value of minimum oxygen concentration. And, finally, low positive values of $D$, which decline to the north of $40^{\circ} \mathrm{N}$, are associated with somewhat increased minimum oxygen values.

Of special significance is the above mentioned tongue of relatively high minimum oxygen values which extends westward to the Gulf Stream through the central part of the region and indicates a raising of the minimum oxygen value in the western Sargasso Sea due to the presence of water having a higher salinity for its temperature than is normal for the western North Atlantic at the depth of the oxygen minimum. This effect is most pronounced between latitudes $25^{\circ} \mathrm{N}$ and $35^{\circ} \mathrm{N}$, and the graphical representation of oxygen plotted as a function of $D$ for stations between these latitudes (Fig. 4 ) shows an approximate straight line relationship in which both high minimum oxygen values and high positive $D$ values decline towards the eastern side of the Gulf Stream. The standard deviations of the oxygen values $\sigma_{0_{2}}$ and the $D$ values $\sigma_{D}$ are:

$$
\begin{aligned}
& \sigma_{0_{2}}=0.178 \\
& \sigma_{D}=4.06
\end{aligned}
$$

and the correlation coefficient, $r$, between the oxygen and $D$ values in this strip:

$$
r=0.782 \text {. }
$$

This indicates that high correlation exists between the minimum oxygen values and the $D$ values in the strip between $25^{\circ} \mathrm{N}$ and $35^{\circ} \mathrm{N}$, extending across the western basin to the eastern edge of the Gulf Stream, and further, illustrates that the raising of minimum oxygen values in the west central Sargasso Sea is the result of an influx from the east of water having a higher salinity than is normal for the region. That this water is of Mediterranean origin is highly probable.

\section{Density}

Examination of available oxygen data from the western basin of the North Atlantic (depths 2000 meters or more) between the equator and $50^{\circ} \mathrm{N}$ and west of the 4 oth meridian (Fig. 5), showed that the observed minimum absolute values of oxygen (expressed as cc per liter) occurred with densities $\left(\sigma_{t}\right)$ between 26.95 and $27.4 \mathrm{I}$. Plotting the density at the depth of the observed minimum oxygen value in this region showed no defined regional variation of density, but rather suggested that the varying $\sigma_{t}$ values associated with the minimum oxygen values were the result of random sampling (page 5), and it seemed entirely likely that, if it were possible to estimate the true minimum oxygen value, it would be found generally to occur everywhere in the western North Atlantic at approximately the same density surface. Thus, in order to test the significance of this hypothesis the following procedure was used.

The observed $\sigma_{t}$ values associated with the observed minimum oxygen values were first grouped into cells having a class interval of 0.04 units of $\sigma_{t}$ and the frequency distribution in table 2 formed. ${ }^{2}$ The general form of this table suggests that the data are

\footnotetext{
2 Data for this calculation were obtained from I 35 oceanographic stations in the western basin of the North Atlantic, the depth at each station being more than 2000 meters; see fig. 5 .
} 


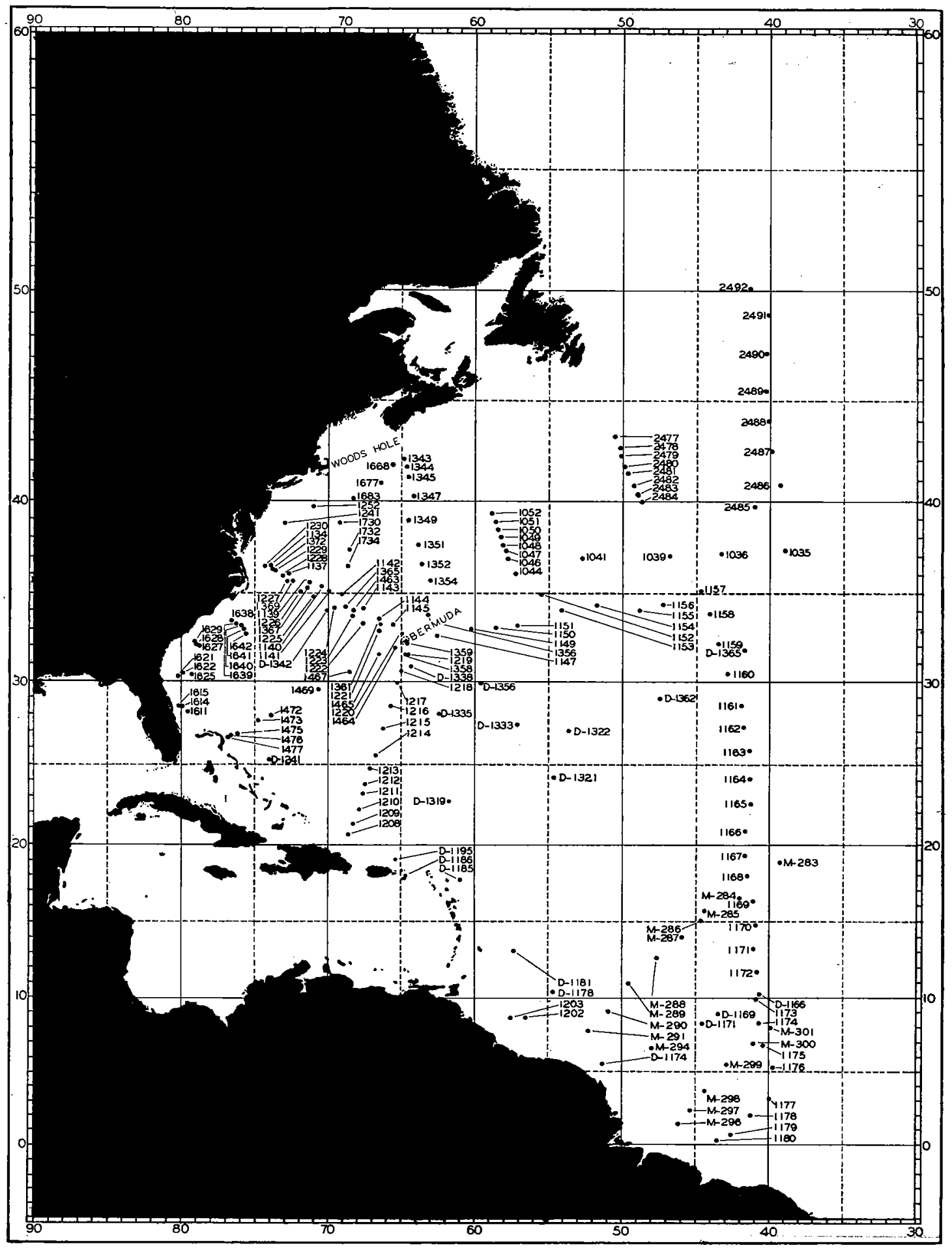

FIG. 5.- - Location of oceanographic stations used in this investigation. Unlettered stations= "Atlantis" stations; D stations= "Dana" stations (Schmidt, I929); M stations="Meteor" stations (Wattenberg, I933). 
normal. Referring the frequency distribution to Bernoulli class marks $(0, \mathrm{r}, 2 \cdots n)$ the first four moments calculated about the Bernoulli mean (6.3II) are:

$$
\begin{array}{lr}
M_{0}= & \mathrm{I} 35.000 \\
M_{1}= & 0.000 \\
M_{2}= & \mathrm{I}, 088.966 \\
M_{3}=- & 264.035 \\
M_{4}= & \mathrm{I} 8,545.557
\end{array}
$$

Class Interval

$$
\begin{aligned}
& 26.93^{-26.96} \\
& 26.97-27.00 \\
& 27.01-27.04 \\
& 27.05-27.08 \\
& 27.09-27.12 \\
& 27.13^{-27} \cdot 16 \\
& 27.17-27.20 \\
& 27.21-27.24 \\
& 27.25-27.28 \\
& 27.29-27.32 \\
& 27.33^{-27}-36 \\
& 27.37-27.40 \\
& 27.41-27.44
\end{aligned}
$$

TABLE 2
Frequency

1
4
10
12
13
13
14
14
18
17
12
12
7
2

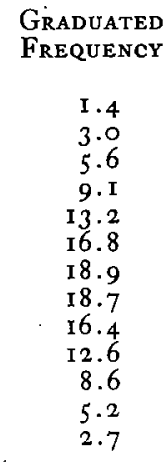

Applying the Sheppard's Adjustments to the above moments to correct for the error made in assuming that all the frequencies in the class intervals are concentrated at the mean value, the adjusted moments become:

$$
\begin{array}{lr}
\mu_{0}= & \mathrm{I} 35.000 \\
\mu_{1}= & 0.000 \\
\mu_{2}= & \mathrm{I}, 077.7 \mathrm{I} 6 \\
\mu_{3}=- & 264.035 \\
\mu_{4}= & \mathrm{I} 8,005.0 \mathrm{I} \mathrm{I}
\end{array}
$$

The standard deviation, ${ }^{3} \sigma$, is then:

$$
\sigma=\sqrt{\frac{\mu_{2}}{\mu_{0}}}=2.825
$$

and the skewness, $S$, :

$$
S=\frac{\mu_{3}}{2 \mu_{0} \sigma^{3}}=-0.04336
$$

indicating a slight skewness to the right. The normal frequency curve best fitting these data is thus:

$$
y=47.788 e^{0.04336(x-6.311 / 2.825)} \frac{\mathrm{I}}{\sqrt{2 \pi}} e^{-1 / 2(X-6.311 / 2.825)^{2}}
$$

and is superimposed on a histogram of the observed frequency distribution in figure 6.

\footnotetext{
3 This is the standard deviation of the data when referred to Bernoulli class marks; the standard deviation when referred to the class marks in table 2 (mid class values) is $\sigma=0.1$ I 30 I.
} 


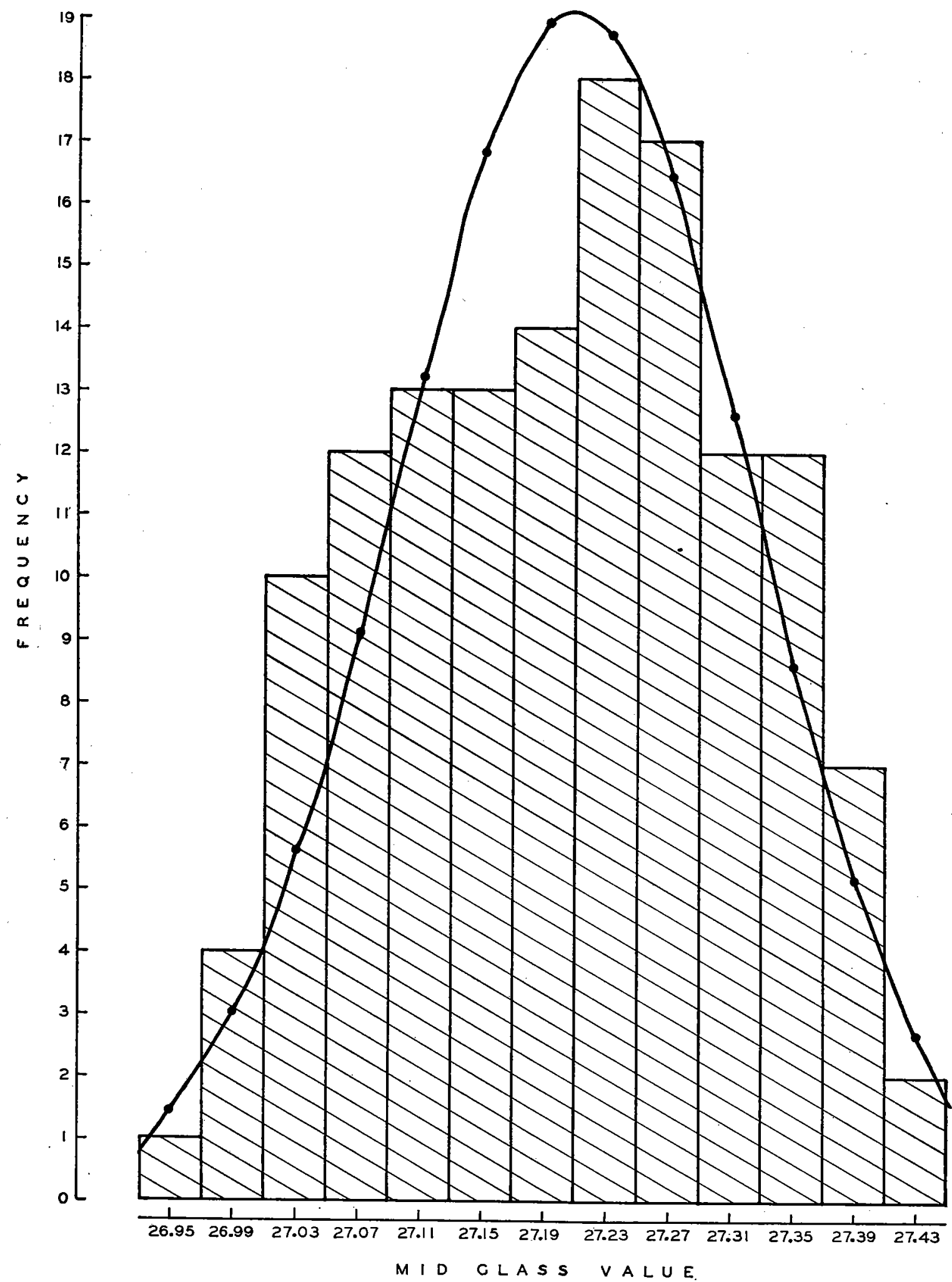

FIG. 6.-Frequency distribution of $\sigma_{t}$ values at depth of minimum oxygen concentration; observed frequency given by histogram; theoretical frequency fitted by normal curve. See text page 12. 
The data are next graduated from this normal frequency curve (table 2) and the Chi squared function calculated as a measure of the goodness of fit. Thus:

$$
\mathrm{X}^{2}=\frac{\left(F_{1}-f_{1}\right)^{2}}{F_{1}}+\frac{\left(F_{2}-f_{2}\right)^{2}}{F_{2}}+\cdots+\frac{\left(F_{n}-f_{n}\right)^{2}}{F_{n}}
$$

where $F$ is the theoretical frequency and $f$ the observed frequency. For the particular problem under consideration:

$$
\mathrm{X}^{2}=9.294^{\mathrm{I}}
$$

since the data are grouped into $\mathrm{r} 3$ cells we find the Pearson probability ${ }^{4}$ :

$$
P=.6774 \text {. }
$$

From which it is concluded that in 67.7 times out of 100 we should get in random sampling a fit as bad, or worse, than that observed if the real distribution was normal. Thus, we can say that the theoretical curve is a good representation of the distribution of $\sigma_{t}$ values associated with the minimum oxygen values (Fig. 6).

The ratio:

$$
\beta_{2}=\frac{\mu^{4}}{\mu_{0} \sigma^{4}}=2.093
$$

and the probable error of

$$
\beta_{2}=\frac{3 \cdot 3044}{\sqrt{\mu_{0}}}=0.285
$$

Since for a normal curve $\beta_{2}=3$ we find for the curve under consideration:

$$
\left|\beta_{2}-3\right|=0.907
$$

which exceeds three times the probable error of $\beta_{2}$ by 0.052 , suggesting that the curve may be slightly hypernormal. The difference, however, is too small to be considered significant, and certainly is not sufficiently definite to classify the curve as hypernormal; so for all practical purposes we may consider the data as being normal.

The mode $\left(M_{0}\right)$ or the most probable value of $\sigma_{t}$ at the minimum oxygen concentration in the western North Atlantic basin is interpolated to be:

$$
M_{0}=L+\frac{C F}{F+f}
$$

where $L$ is the lower limit of the modal class, $C$, the class interval, $F$, the frequency of the class above the mode, and, $f$, the frequency of the class just below the mode. For the problem under consideration:

$$
M_{0}=27.232 \neq 0.008
$$

And, since three times the probable error is not likely to be exceeded we tentatively place as the limits of $\sigma_{t}$, between which the minimum oxygen value in the western North Atlantic tends to occur, as:

$$
\sigma_{t}=27.207 \text { to } 27.257
$$

${ }^{4}$ See Pearson (1930). 
Thus, the above analysis indicates that everywhere in the western North Atlantic (west of $40^{\circ} \mathrm{W}$ ), between the equator and $50^{\circ} \mathrm{N}$, when the water is more than 2000 meters deep, regardless of the depth, the minimum oxygen value will tend to occur along a surface of equal density $\left(\sigma_{t}\right)$ whose most probable value is 27.232 and whose limits are 27.207 to 27.257 .

This conclusion may be tested from the results of station $2639\left(66^{\circ} 25^{\prime} \mathrm{W}, 35^{\circ} \circ 7^{\prime} \mathrm{N}\right)$ where a sampling of the water column was carried out approximately every 20 meters between 730 and 980 meters depth, so that with a high degree of approximation the absolute minimum oxygen value, together with its temperature, salinity, and density was determined. The results in the vicinity of the minimum oxygen value at this station are given in table 3 .

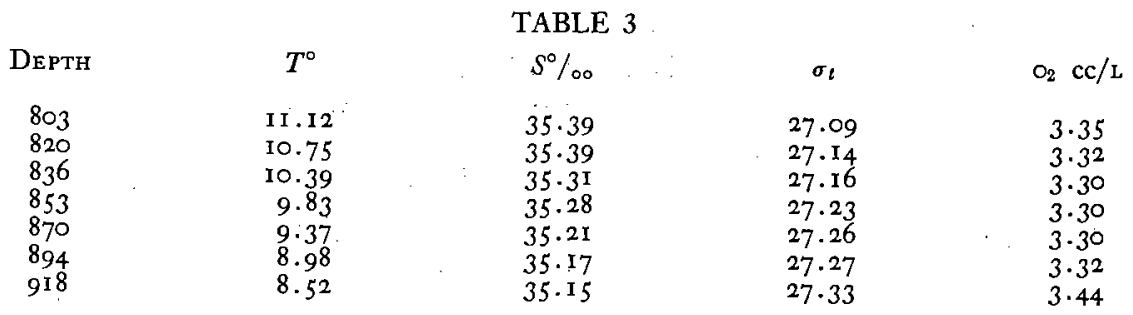

The minimum oxygen value at 853 meters with a value of 27.23 is in agreement with the theoretical value of $27.232 \neq 0.008$.

\section{PHYSICAL SIGNIFICANCE OF THE ORIGIN OF THE MINIMUM OXYGEN CONCENTRATION}

From general knowledge it would seem that the development and maintenance of the oxygen minimum at mid depths might result from either one or from a combination of the following reasons. These are: $\mathrm{r}$, the biological physical relationships of the water column which, under favorable conditions (in the absence of intense vertical transfer), may cause a maximum proportion of oxygen consumption to occur at certain levels because of specific gravity relationships of the water itself and decomposing organic matter; or 2 , the presence at mid depths of a relatively slow moving, stagnating layer of water (such a layer as might result under certain conditions at the boundary between two currents).

The concept that the principle oxygen minimum in the North Atlantic might result primarily from a slower horizontal renewal of water at the depths concerned was suggested by Jacobsen (I9I6) and the question of the origin of the minimum oxygen zone in the Atlantic has subsequently been discussed by Wattenberg (I929), LeDanois (I 934), Seiwell (I 934), and Wüst (I935). These authors offered various opinions as to the origin of the minimum oxygen concentration, but the problem is resolved into two hypotheses as indicated above; or, stated in other words, whether the minimum concentration is primarily the result of a proportionately greater oxygen consumption per unit time (with respect to the supply) or primarily the result of a slower renewal by horizontal currents. Thus, evidence supporting the former hypothesis was obtained as a result of an analysis of "Atlantis" observations along the 4oth meridian which appeared to indicate that the water making up the oxygen minimum layer (or oxygen poor layer) was not moving any slower than the oxygen richer water immediately below (Seiwell, I934). 
And at that time the opinion was expressed in favor of predominating biological, rather than dynamical causes as being responsible for producing and maintaining the oxygen minimum at mid depths.

However, the idea that the principal oxygen minimum arises because of the presence of a very slowly moving, or actually resting, layer of water at mid depths has recently again been brought into prominence by Wüst (I935) in support of his conception of the Atlantic circulation which defines the nuclei of seven different water masses on the basis of the horizontal distribution of intermediate salinity maxima, intermediate salinity minima and intermediate oxygen maxima characterizing the vertical distribution of those properties. In order to fix the boundaries between these water masses Wüst points to the vertical distribution of oxygen as a useful criterion in that (as he suggests) the presence of minimum oxygen values (points of inflection in the curve characterizing the vertical distribution of oxygen) are dynamically conditioned by the presence of stagnating or very slowly moving horizontal currents such as would characterize the boundary layers between the various water masses. ${ }^{5}$.

Thus, on the basis of three longitudinal sections through the Atlantic Wüst distinguishes three minimal concentrations in the vertical distribution of oxygen, but of these only one, i.e., the principal oxygen minimum, is considered here. This oxygen minimum occurring at mid depths (I00 to 950 meters) has been traced from $45^{\circ} \mathrm{S}$ to $55^{\circ} \mathrm{N}$ in the Atlantic and is assumed by Wüst to be identical with the upper boundary of the subantarctic water between $45^{\circ} \mathrm{S}$ and $20^{\circ} \mathrm{N}$, and identical with the upper boundary of the Mediterranean water between $20^{\circ} \mathrm{N}$ and $55^{\circ} \mathrm{N} .{ }^{6}$

Dietrich (1936) has made use of Wüst's concept in an attempt to approximate absolute velocities of water movement in the Gulf Stream and the Agulhas current. Briefly, his method was to refer relative velocities (as calculated from the Bjerknes circulation theorem) to a zero velocity level, which level he assumed was indicated by the depths of the minimum oxygen concentration. Thus, the situation as stated by Dietrich is: "Das Sauerstoffminimum kann in der Tiefe nur durch zwei Faktoren erklärt werden. Entweder es findet ein seitlicher Einschub sauerstoffarmen Wassers statt, oder es handelt sich um eine verhältnismässig ruhende Schicht, in der fortgesetzt Sauerstoff durch die Oxydation der sinkenden, abgestorbenen Organismen verbraucht wird." It should be noted that the minimum oxygen concentration in the open sea cannot be maintained to any great extent solely by an influx of oxygen poor water since the same factors required to produce lowered oxygen pressure would need be continuously at work to maintain it against influences acting in the opposite direction.

Thus, it seems that both Wüst and Dietrich, in their efforts to make the minimum oxygen concentration serve some useful purpose, have attached too little significance to the influence of variation in the rate of oxygen consumption with depth. We do not think that any method which does not consider biological factors is sufficient to determine the origin of the minimum oxygen concentration.

Further significance is given this discussion by considering Rossby's (1936) comment

\footnotetext{
${ }^{5}$ Wüst (1935, page 206) states: "Die intermediären Sauerstoffminima charakterisieren die Schichten schwächster Durchlüftung." And still further we find: "Die intermediären Sauerstoffminima der Stratosphäre sind also in erster Linie dynamische bedingt, sie kennzeichnen die nahezu ruhenden Grenzschichten Zwischen den verschiedenen Gliedern der Tiefenzirkulation."

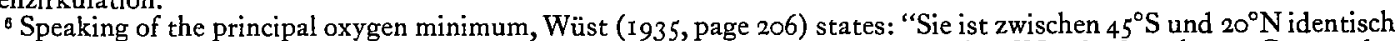
mit der oberen Grenze des subantarktischen Zwischenwassers, zwischen $20^{\circ} \mathrm{N}$ und $55^{\circ} \mathrm{N}$ mit der oberen Grenze des Mittelmeerswassers und kann zugleich aufgefasst werden als die untere Grenze der 'Troposphäre."
} 
on Dietrich's method of using the minimum oxygen concentration at mid depths as a zero level for calculations of the velocity of the Gulf. Stream, which assumption by necessity implies that below the minimum oxygen concentration there is a fairly strong counter current. Thus, the dynamic topography of the individual isobaric surfaces computed by Dietrich (1936) shows the Iooo decibar surface as dropping about 24 dynamic centimeters from left ("Atlantis" station 1229) to right (station I227) across the Gulf Stream in a distance of about 93 kilometers; which would call for a mean upstream velocity of about 28 centimeters per second at a depth of rooo meters. Moreover, as Rossby points out, evidence shows that below I000 meters the water column is heavier at "Atlantis" station 1229 than at station 1227 from which it follows that the mean upstream velocity between these two stations at levels below rooo meters must be greater than 28 centimeters per second. And, since the depth of the water is approximately 4000 meters, Dietrich's assumption implies that the upstream transport of water below 1000 meters must be in excess of $78 \times 10^{6} \mathrm{~m}^{3} \mathrm{sec}^{-1}$ which is more than twice the amount which Dietrich has calculated for the downstream transport of the Gulf Stream $\left(3 \mathrm{I} \times \mathrm{IO}^{6} \mathrm{~m}^{3} \mathrm{sec}^{-1}\right) .^{7}$

Consideration may also be given to the results at "Atlantis" station 2639 where the vertical distributions of oxygen (cc per liter and per cent saturation), salinity, temperature, and density through the region of minimum oxygen concentration are shown in detail (observations approximately 20 meters apart) in figure I. For comparison, on the right hand side of this figure, the mean oxygen and temperature distributions to 3000 meters depth are given for this station.

The lowest oxygen values occurred as usual in the most stable part of the water column. The detailed part of figure I illustrates that the minimum absolute quantity of oxygen occurred at 853 meters. Between 804 and 903 meters, the absolute oxygen content was nearly uniform, hence, according to the assumption that the minimum oxygen value is determined primarily by dynamic processes this thin layer would represent the part of the water column where horizontal velocities were lowest, or even zero. Such an assumption, also by necessity, implies that the curve for vertical distribution of oxygen represents a vertical current profile, and, on the basis of an approximately uniform oxygen consumption throughout the water column (which is also implied by the above assumption), then there should be an increase in current velocity not only upward from a depth of 853 meters to attain a maximum near the surface but a similar downward increase in current velocity from this same depth to a maximum at about 2000 meters from which depth there would be but little diminution in velocity all the way to the bottom. Such a current profile is, however, contradicted by our general knowledge of the oceanography of this region. In this particular case additional support is given to the improbability or erroneous character of this inferred vertical current profile by the fact that during the five day period of observation at station 2639 significant inclinations of the hydrographic wire from the vertical (up to $36^{\circ}$ ) were confined entirely to the upper I IOO-I 200 meters of the water column; in still deeper water the wire inclination (between top and bottom water bottle) was only $6^{\circ}-7^{\circ}$, indicating much less current (for details see Seiwell, r 937).

Evidence of another sort that the minimum oxygen concentration may occur within a current, and not at its boundary, has been brought out recently by an application of

\footnotetext{
${ }^{7}$ See Iselin (1936).
} 
the Wake stream theory to the Gulf Stream (Rossby, I936), where it has been shown, both from theoretical and practical considerations, that a mass exchange occurs in a down stream direction between the Gulf Stream and its surroundings, which results in an absorption of Sargasso Sea water along the right edge of the Gulf Stream and a corresponding discharge of water from the left edge. Thus, according to this concept, which is substantiated by a study of temperature salinity and oxygen salinity correlations across the Gulf Stream (particularly the latter between Straits of Florida and Nova Scotia), a mechanism is provided whereby water may be transferred from the open ocean basin across the Gulf Stream and into the limited slope water over the continental slope. An extremely significant point in the analysis is that the minimum oxygen concentration within the Gulf Stream increases in a down stream direction ${ }^{8}$ corresponding to the higher minimum oxygen values of the central Sargasso Sea (Fig. 2, page Io). The downstream increase of minimum oxygen values within the Gulf Stream appears to be the result of absorption of Sargasso Sea water along the isopycnal surface of the minimum oxygen concentration (page I5) thus indicating that the minimum oxygen value occurs within the current itself and not at its lower boundary. The biological factors acting to maintain the minimum within the Gulf Stream are essentially the same as those within the Sargasso Sea.

The above considerations show that the occurrence of a minimum oxygen concentration at mid depths in the sea is not so simple a phenomenon that sweeping and far reaching conclusions can be drawn as to relationship of current velocity to oxygen distribution. Indeed, it is common knowledge that biological conditions in the sea are far from uniform; in many cases, or perhaps always, they are regulated by the physical and chemical structure of the water, and variations in the rate of oxygen consumption with depth are likely to play a significant part in determining the vertical distribution of oxygen. We have here a problem of far reaching importance.

\section{SUGGESTIONS CONCERNING THE ORIGIN OF THE MINIMUM OXYGEN CONCENTRATION}

The concept that the minimum oxygen concentration at mid depths in the Atlantic is directly the result of a stagnating layer of water finds but little support among the existing oceanographic evidence. In fact it appears to me that recent investigations show little attempt to support this particular concept, but rather the tendency has been to accept it without due regard to the possible effect of vertical variations of biological activity on the vertical distribution of oxygen (page I9).

The stagnant layer concept of the origin of the minimum oxygen concentration appears, by necessity, to imply two significant assumptions: i.e., that both above and below the depth of the minimum oxygen concentration there is a continuously increasing

\footnotetext{
8 Oxygen consumption should cause the oxygen minimum concentration to decrease in the absence of addition of oxygen from without. However, Rossby (1936, page 33), referring to my own investigation (Seiwell, 1934), has misjudged the annual oxygen consumption in the minimum oxygen layer of the Sargasso Sea to be about 0.1 cc per liter. This investigation of oxygen consumption referred to was obtained from a line of observations along the 4 oth west meridian ("Atlantis" stations II $57-$ II 79) between the equator and latitude $35^{\circ} \mathrm{N}$. The average annual oxygen consumption in the oxygen poor layer (or minimum oxygen layer) as calculated by me for this oceanographic section was:

North of latitude $15^{\circ} \mathrm{N}$, annual consumption $=0.34$ to $0.63 \mathrm{cc} /$ liter South of latitude $I^{\circ} \mathrm{N}$, annual consumption $=0.31$ to $0.4^{2} \mathrm{cc} /$ liter Between equator and $35^{\circ} \mathrm{N}$, annual consumption $=0.42 \mathrm{cc} /$ liter
} 
horizontal current velocity (attaining maximum velocities in the overlying water near the surface and in the underlying water where the oxygen gradient ends, from whence relatively high velocities persist to the bottom), and also that the oxidation of organic matter is relatively uniform over a large part of the water mass which has been shut off from direct communication with the surface layer of the sea. Neither of these assumptions can be regarded as proven by existing information.

On the other hand, from general oceanographic knowledge, it seems probable that the biological activity of the water mass plays an important role in fixing the minimum oxygen concentration at mid depths. This may be brought about either by a maximum concentration of oxidizable organic matter at the depth of the oxygen minimum concentration, or (if the supply of oxygen by horizontal currents varies with depth) by vertical variations of biological activity causing the ratio $\mathrm{O}_{2}$ utilized $/ \mathrm{O}_{2}$ supplied to be continuously increased as the depth of the minimum oxygen concentration is approached both from above and below. With reference to the former possibility, an increased concentration of oxidizable organic matter in the vicinity of the oxygen minimum concentration may be suggested by the fact that the minimum concentration in the Western North Atlantic tends to occur at the density value, $\sigma_{t}=27.232 \neq 0.008$ (page $1_{4}$ ), which implies that the settling velocities of organic particles are perceptibly slowed up in the vicinity of the minimum concentration, resulting in an increase of oxygen consumption per unit time. However, the results of oceanic biological investigations have not yet furnished evidence for the adoption of this hypothesis.

A plausible explanation is afforded by the possibility that a minimum oxygen concentration would be produced at an intermediate level if the balance of oxygen consumption over supply was greater than at other depths, even if this be not the level where concentration of oxidizable matter be greatest or horizontal circulation weakest. Such a situation is illustrated by the hypothetical example in table 4 , where both the supply and the consumption of oxygen per unit mass of water per unit time decrease with increasing depth, but the balance of oxygen consumption over supply attains a maximum value at an intermediate depth (600 meters).

TABLE 4

\begin{tabular}{|c|c|c|c|}
\hline DEPTH & $\begin{array}{l}\mathrm{O}_{2} \text { Consumption } \\
\text { cc PER Unit Time }\end{array}$ & $\begin{array}{c}\mathrm{O}_{2} \mathrm{SUPPLY}_{\text {CC PER UNIT TIME }} \\
\text { U }\end{array}$ & $\frac{\mathrm{O}_{2} \text { Consumption }}{\mathrm{O}_{2} \text { SuPply }}$ \\
\hline 0 & 6.00 & 9.50 & $0.63^{2}$ \\
\hline 200 & 5.84 & 8.24 & 0.709 \\
\hline 400 & $5 \cdot 36$ & $6.9^{7}$ & 0.768 \\
\hline 600 & 4.56 & $5 \cdot 72$ & 0.797 \\
\hline 800 & $3 \cdot 44$ & $4 \cdot 46$ & 0.77 I \\
\hline 1000 & 2.00 & 3.20 & 0.625 \\
\hline
\end{tabular}

If in any water mass dependent for its oxygen supply primarily on horizontal currents, decreasing in velocity from top to bottom, the oxygen consumption was constant over the entire column the balance of oxygen consumption over supply will be a maximum at the level where the supply of oxygen is taking place at the slowest rate. This is essentially the mechanism proposed by the stagnant layer concept of the minimum oxygen concentration (page I5). If, however, the oxygen consumption in this water column changes with depth (due to the density relationship between the water and organic debris) in such a way that in the upper part the percental decline of consumption with depth is less than the percental decline of supply (by horizontal currents) and that 
in the lower part the percental decline of consumption is greater with depth than the percental decline of supply, the balance of oxygen consumption over supply may attain its maximum at some intermediate depth. And, this will be represented in the vertical distribution of oxygen as the minimum oxygen concentration. Therefore, the existence of the latter does not necessarily imply a minimum horizontal supply of oxygen. Near the origin of the water mass (where it is freshly aerated) the minimum concentration may be barely perceptible, but as time proceeds (as the water mass is farther removed from its origin) the vertical oxygen gradient will, under the influence of the above factors,

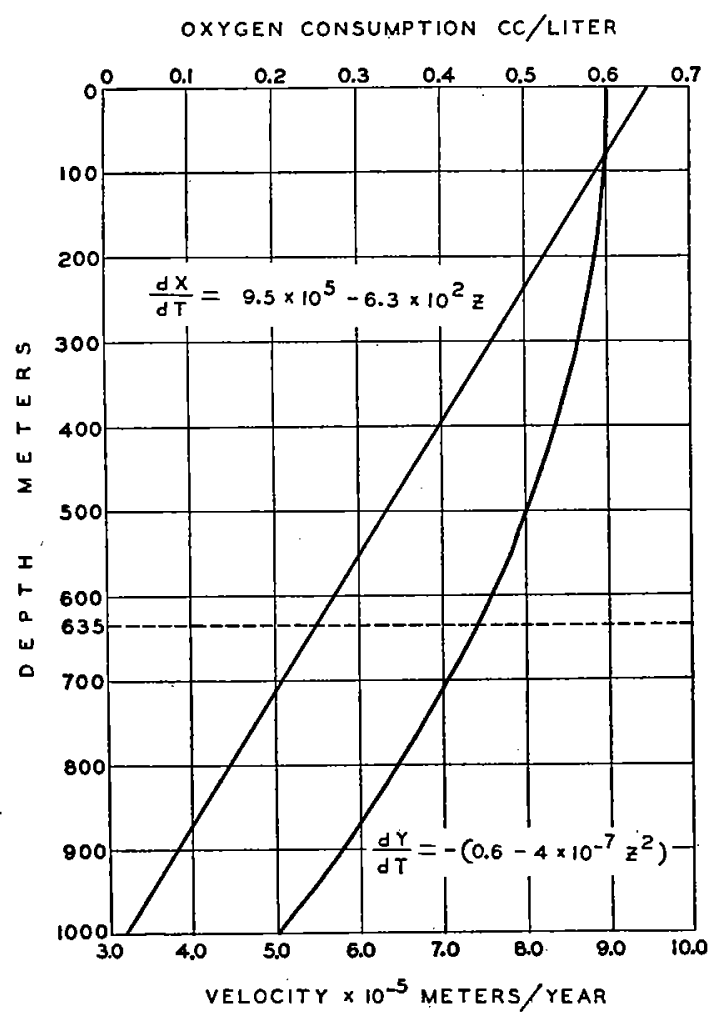

FIG. 7.-Assumed vertical variation of oxygen consumption and horizontal velocity in the hypothetical water layer of 1000 meters thickness. See text for explanation.

increase and the minimum concentration become more pronounced. This possibility is illustrated by the following hypothetical example.

For purposes of illustration a layer of water, I000 meters thick, completely shut off from contact with the air or any other sources by which oxygen may be supplied, will be considered, and any horizontal or vertical turbulence which would naturally effect the oxygen content of this layer of water will be disregarded, so that its only source of oxygen is by means of horizontal currents. Also, let it be supposed that the entire layer of water is moving in one direction only and that at its initial end, which will be termed the origin, the oxygen content is everywhere uniform from top to bottom. The problem is then formulated with the aid of the following premises: (a) that the horizontal current velocity is constant for any particular depth, $Z$, but varies in a vertical direction, continuously 
decreasing from top to bottom (o to I000 meters); (b) that the rate of oxygen consumption is constant for any particular depth $Z$ but varies in a vertical direction, continuously decreasing from top to bottom. The numerical data for this illustration are not results of actual observation, since such information is not available for the open ocean, but the orders of magnitude of the numerical values are, at least, approximately correct.

The vertical variation of current velocity within the layer is assumed to be given by:

$$
V=\frac{d X}{d t}=9.5 \times 10^{5}-6.3 \times 1 \circ^{2} Z \text { meters per year }
$$

where $Z$ is the depth in meters (reckoned as positive downward); $X$ the distance from the origin in meters; the time, $t$, is expressed in years. The vertical variation of velocity with depth is graphically illustrated by figure 7 . The mean velocity for the layer is:

$$
V_{M}=\frac{I}{I 000} \int_{0}^{1000}\left(9.5 \times 10^{5}-6.3 \times 10^{2} Z\right) d Z=6.35 \times 10^{5} \text { meters per year }(1.9 \mathrm{cms} \text { per sec. })
$$

which is the same order of magnitude as given by estimations for the deep ocean basins. ${ }^{9}$

The vertical variation of oxygen consumption within the hypothetical layer is assumed to be given by:

$$
\frac{d Y}{d t}=-\left(0.6-4 \times 10^{-7} Z^{2}\right) \text { cc per liter per year }
$$

and the mean rate of oxygen consumption for the entire layer is:

$$
\frac{d Y_{M}}{d t}=\frac{1}{1000} \int_{0}^{1000}-\left(0.6-4 \times 10^{-7} Z^{2}\right) d Z=-0.467 \mathrm{cc} \text { per liter per year }
$$

which is the same order of magnitude as given by estimations for the deep ocean basins. ${ }^{10}$

In the upper part of the water column the percental decline of oxygen consumption with depth is less than the percental decline of current velocity on which the oxygen supply to various horizontal levels is dependent, but in the lower part the reverse occurs. A condition such as illustrated by figure 7 may occur in nature because of specific gravity relationships between the water and organic debris; the reduced rate of oxygen consumption in the still deeper water being the result of less organic materials reaching the levels in question.

The problem is now formulated with reference to a coordinate system which moves along with the layer. Thus:

$$
\frac{d Y}{d t}=-\left(0.6-4 \times 10^{-7} Z^{2}\right)
$$

and since for any level $Z$

$$
\frac{d X}{d t}=V
$$

\footnotetext{
9 The mean horizontal velocity of the oxygen poor layer, approximately 1000 meters thick, in mid Atlantic between equator and $11^{\circ} \mathrm{N}$ latitude, has been estimated to be about 1.2 to 1.5 centimeters per second (Seiwell, I934).

10 The mean annual oxygen consumption in the oxygen poor layer of mid Atlantic, between equator and $32^{\circ} \mathrm{N}$ latitude, has been estimated to be about $0.42 \mathrm{cc}$ per liter per year( Seiwell, I934).
} 
where $X$ is the horizontal distance from the origin, measured in meters, equation I becomes:

$$
\frac{d Y}{d X}=-\frac{0.6-4 \times 10^{-7} Z^{2}}{9.5 \times 10^{5}-6.3 \times 10^{2} Z}
$$

Integrating:

$$
Y=8-\frac{0.6-4 \times 10^{-7} Z^{2}}{9 \cdot 5 \times 10^{5}-6.3 \times 10^{2} Z} X
$$

where 8 is the constant of integration so chosen as to represent an arbritrary oxygen

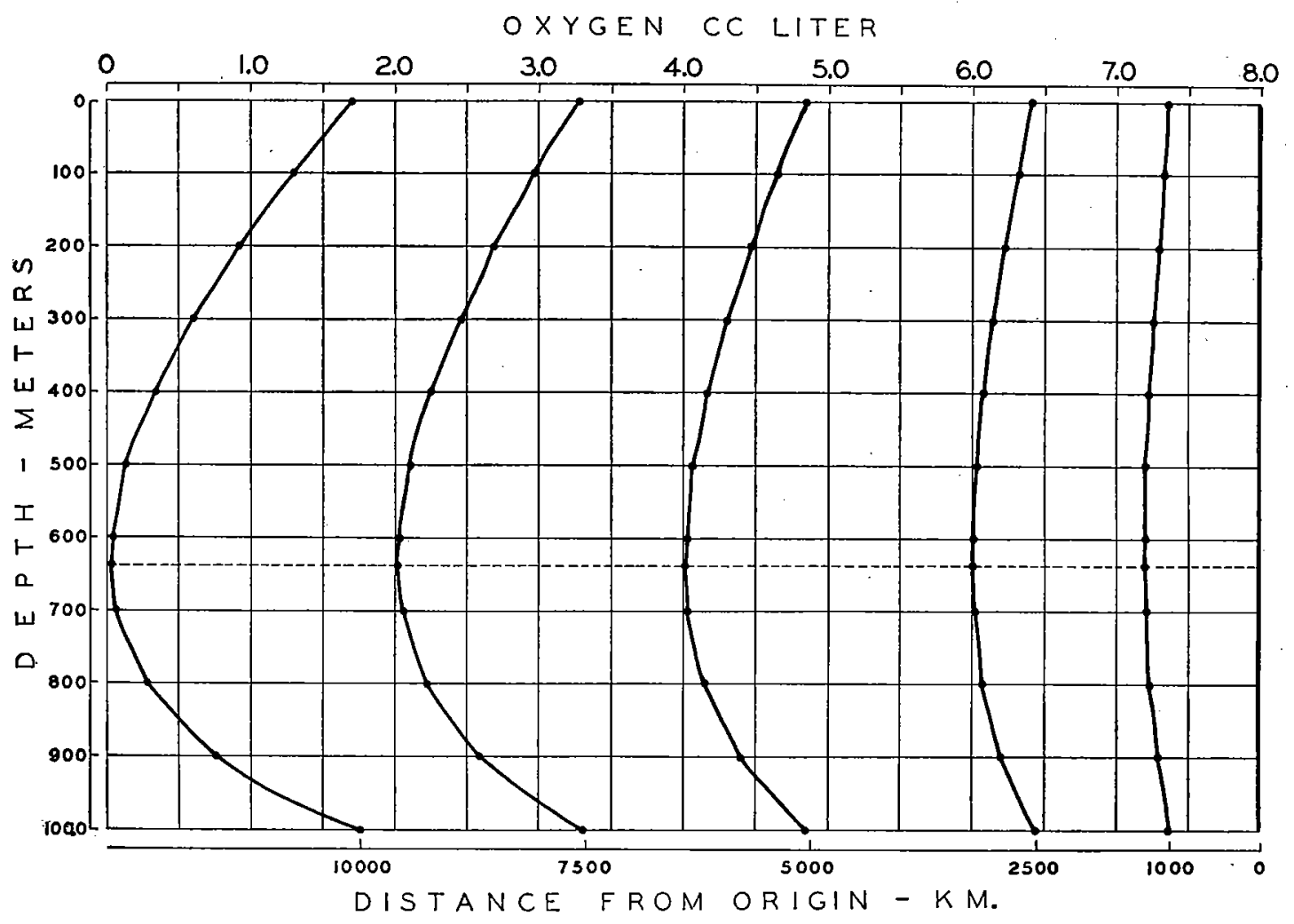

FIG. 8.-Calculated vertical distribution of oxygen in the hypothetical water layer of rooo meters thickness at distances of $0,1000 \mathrm{~km}, 2500 \mathrm{~km}, 5000 \mathrm{~km}, 7500 \mathrm{~km}$ and $10,000 \mathrm{~km}$ from the origin. See text for explanation.

content of the water (in cc per liter) at the origin end of the layer $(X=0)$. Equation 3 may now be used to determine the vertical variation of oxygen in the hypothetical layer at any horizontal distance $X$ from the origin.

To find the depth of the minimum oxygen concentration at any distance $X$ from the origin, equation 3 is minimized, thus:

(4)

$$
25.2 \times 10^{-5} Z^{2}-76.0 \times 10^{-2} Z+3.78 \times 10^{2}=0
$$


and the significant root of this equation:

$$
Z=635 \text { meters }
$$

represents the depth at which the minimum oxygen concentration will occur in the hypothetical layer under the conditions outlined above.

The vertical distributions of oxygen for distances $(X)$ of $0,1000,2500,5000,7500$, and 10,000 kilometers from the origin, as calculated from equation 3 , are represented in figure 8 . The minimum oxygen value for all verticals occurs at 635 meters depth, and its intensification with increasing distance from the origin is clearly illustrated.

As stated previously the numerical values used in the above illustration are hypothetical, although their order of magnitude has been guided by results of oceanographic investigations. The problem is given as a means of illustrating the idea that the minimum oxygen concentration in the open ocean can originate and be maintained at mid depths in the presence both of a continuously decreasing horizontal current velocity and rate of oxygen consumption, without necessitating the introduction of either of the assumptions that a minimum horizontal current velocity, or a maximum oxygen consumption coincides with the depth of the minimum oxygen concentration.11

It should be noted that none of the above mentioned vertical variations of biological characteristics need necessarily be of a large order of magnitude at any particular vertical in order to produce the required effect, since the observed vertical variation of oxygen at any station is a product of the past life history of the water mass and the effects of infinitely small processes may be magnified many fold (Fig. 8).

${ }^{11}$ I am indebted to Prof. Henry B. Phillips and Dr. George P. Wadsworth of the Massachusetts Institute of Technology for their interest in this problem. 


\section{LITERATURE}

Dietrich, G.

I936 Aufbau und Bewegung von Golfstrom und Agulhasstrom. Naturwissenschaften, 24 Jahrg., Heft I 5, pp. 225-230.

Helland-Hansen, BJ $\phi$ RN

I930 Report of the scientific results of the "Michael Sars" North Atlant. deep-sea exped. I910. Vol. I. Physical Oceanography and Meteorology. Part I (text), I 5 pp.

IsELIN, C. O'D.

I936 A study of the circulation of the western North Atlantic. Papers in Physical Oceanography and Meteorology. Vol. IV, No. 4, IOI pp.

JACOBSEN, J. P.

I9I6 Contribution to the hydrography of the Atlantic. Medd. Komm. Havunders $\phi-$ gelser. Serie: Hydrografi. Bd. I I, 23 pp.

LeDanois, Ed.

1934 Les transgressions océanique. Off. Sci. Tech. Pêchs Maritimes, Revue des Travaux. Tome VII, Fasc. 4, No. 28, pp. 369-462.

Pearson, Karl

I930 Tables for statisticians and biometricians. Part I. Ed. III. Biometric Laboratory, University College, London. I $43 \mathrm{pp}$.

Rossiy, C.-G.

I936 Dynamics of steady ocean currents in the light of experimental fluid mechanics. Papers in Physical Oceanography and Meteorology. Vol. V, No. I, 43 pp.

Schmidt, Johannes

1929 Introduction to the oceanographical reports. Danish "Dana" Expeditions I 920-I 922. No. I, 87 pp.

Seiweld, H. R.

I 934 The distribution of oxygen in the western basin of the North Atlantic. Papers in Physical Oceanography and Meteorology. Vol. III, No. I, 86 pp.

I937 Short period vertical oscillations in the western basin of the North Atlantic. Papers in Physical Oceanography and Meteorology. Vol. V, No. 2, 44 pp.

Watten berg, Hermann

I933 Das chemische Beobachtungsmaterial und seine Gewinnung. Wiss. Ergeb. Deut. Atlant. Exped. "Meteor" I925-I927. Bd. VIII, pp. I-I I7.

I929 Die Durchlüftung des Atlantischen Ozeans. Journ. du Conseil, Vol. IV, No. I, pp. 68-79.

Wüst, GEORG

I 935 Schichtung und Zirkulation des Atlantischen Ozeans. Die Stratosphäre. Wiss. Ergeb. Deut. Atlant. Exped. "Meteor" 1925-I927. Bd. VI, teil I, I80 pp. 